\title{
Support from the
}

\section{Administration: A Case}

\section{Study in the Implementation of a Grassroots Faculty Development Program}

\section{Harry G. Lang}

\section{James J. DeCaro}

National Technical Institute for the Deaf

Rochester Institute of Technology

In their study of Bush Foundation faculty development programs, Eble and McKeachie (1985) discuss the importance of "knowing the faculty." Both administrators and faculty developers should be aware of faculty attitudes and their role in determining the kind of faculty development programming that can be effective at a college or university. Among the sources of satisfaction reported by faculty in the successful Bush Foundation programs was a sense of accomplishment in learning skills and developing new competencies in an academic environment that fostered independence. Successful development programs, Eble and McKeachie argue, are encouraged by a decision structure that involves the faculty in goal setting, planning, and governance. They also write that administrative support represents a crucial aspect of this independence, and that both the independence and the accompanying satisfaction are predominantly intrinsic factors that characterize not only successful faculty development programs, but effective teachers as well.

As the coordinator of the Office of Faculty Development (OFD) and Dean of the College, we will take a participant-observer perspective in 
describing how a centralized faculty development program evolved into one based on an effective grassroots approach. We take Eble and McKeachie's view that non-intrusive administrative support is most effective in encouraging the implementation of a faculty development program. Indeed, faculty development personnel at our college and the faculty in general agree that the program would not have met with much success without the dean's commitment to faculty responsibility for and authority over their own professional development. This article describes some strategies that administrators and faculty development liaisons may find successful in implementing a grassroots model.

\section{Assumptions at the Dean's Level}

Our college is federally funded and one of nine colleges at a private comprehensive technical university, the Rochester Institute of Technology (RIT). The college has as its primary goal the preparation of deaf people for the workplace and the larger society, so that they can compete on a par with their hearing peers. More than 1,200 deaf students are instructed in our college or mainstreamed with support services into various career programs in the eight other colleges of RIT.

The 280 faculty members in the college teach and conduct research in three schools and three divisions. Many of them are hired from business and industry and are not trained as teachers. Others are well prepared in the theory and practice of teaching, but need to remain current in their fields of expertise as well as in innovative teaching and research techniques. The wide range of faculty development needs of these professionals was an important consideration fueling the movement to a grassroots approach; a centralized model simply could not respond to the wide array of needs from division to division. In other words, the underlying assumption on which we based the decision to move from a centralized model to a division-based model is that "faculty are responsible for their own professional development." As a starting point in implementing the grassroots concept, the dean developed a position statement for the college in concert with the assistant deans of the schools and divisions and the coordinator of the Office of Faculty Development: "Faculty and professionals are to be responsible for their own development and they must participate as full partners in defining the professional development experiences they need to remain current."

Two assumptions are important corollaries to this statement. First, our faculty members know best their own needs for professional development and can be entrusted with the responsibilities of planning, im- 
plementing, and evaluating a program to meet those needs. Second, a successful program cannot be implemented without appropriate human and fiscal resources.

\section{Strategies to Facilitate the Faculty Development Program}

\section{Support at the Dean's Level}

With these assumptions and the importance of remaining unintrusive in mind, we sought ways to support the faculty development program within the constraints of other pressing concerns and the competing demands of college affairs. We determined that the support must be highly visible. The dean, therefore, placed faculty development as a priority on his agenda and that of the college's administrative team. He communicated his sense of the importance of this priority at his opening presentation to the faculty each year and in the college guidance paper issued annually to initiate the college planning cycle. Faculty development was also a prominent item on the college deans' council agenda and appeared regularly in the minutes of the council. These minutes are distributed to chairpeople, who make them accessible to department faculty.

\section{Faculty Forums}

As an initial supportive strategy in the transition to a grassroots program at our college, the dean held meetings with faculty members to discuss the implications of the professional development statement. At these meetings, he explained his intention of providing the faculty with the responsibility and authority to plan, implement, and evaluate the faculty development program.

\section{Reorganization}

A tangible indicator of support during the early stage of the transition was the reorganization of the Office of Faculty Development (OFD) so that its coordinator reported directly to the dean. It was the dean's decision that such an organizational structure was necessary at least until the faculty had acquired full ownership of the program. Prior to this, the office had been under the auspices of a division that provided educational support services. With the reorganization, the OFD became a support mechanism for planning and facilitating the college's faculty development efforts. Simultaneously, the office was given responsibility for providing 
in-service training for new faculty members and assistance to chairpersons in the development of skills related to the observation and evaluation of teaching. The dean's reorganization strategy made faculty development a priority for each of the six assistant deans as well.

\section{Faculty Development Liaisons}

A network of faculty development liaisons was established to facilitate school and division faculty development efforts. A faculty development liaison elected by the division's faculty may be assigned up to 50 percent released time. These positions have three-year terms, although shorter assignments are possible. The liaisons chair the divisional faculty development advisory committees consisting of one representative from each academic department and serve as members of the institute-level planning group coordinated by the OFD. The dean provides funds to departments to hire adjunct faculty, when necessary, to cover some of the faculty development liaison's normal responsibilities.

The faculty development liaison position provides faculty members with opportunities to exercise administrative responsibilities and acquire new skills. Since most of our liaisons to the Office of Faculty Development are not formally trained as faculty developers, OFD provides the resident faculty development expertise. The two full-time faculty members in OFD have between them more than 15 years in the business of faculty development; both have completed dissertations in curriculum and development. They are recognized within and outside the college for their faculty development expertise. These two faculty members advise, counsel, and train the liaisons in carrying out their responsibilities.

Our faculty development liaisons are thus less involved with direct training than with programming faculty development activities and bringing faculty development experts to their divisions. For this reason, the contacts they make at the annual POD conferences are valuable. The conference assists them in their own professional development by increasing their awareness of pertinent issues and by bringing them into contact with faculty developers whom they may wish to invite to speak to their colleagues in their home divisions. A review of the faculty development liaison reports over the past few years reveals many such benefits: "I believe that school-based faculty development is an opportunity to enhance the quality of life for faculty members by providing opportunities for professional and personal renewal and growth," wrote one. "My being a liaison has provided me with such opportunities." 


\section{Faculty Development Advisory Committees}

Service on the school and division faculty development committees also provides faculty members with opportunities to coordinate programming. Committee members share responsibilities for planning and implementing program components, hosting outside speakers, and assisting with needs assessments and program evaluations at the department level. In effect, the college's faculty development program consists of six divisional programs plus collaborative programming across divisions and schools.

\section{Ongoing Dialogue and Program Visibility}

At least once a year, the dean and assistant deans meet as a group with all the faculty development liaisons to discuss plans and concerns. The dean may also attend planning group meetings, when invited, to participate in discussion of particular issues. In addition, the faculty development liaisons meet with the school and division committees on a regular basis to plan individual programs, and they meet weekly as a group to discuss common concerns and programming.

To boost program visibility, the dean has referred colleagues to faculty developers for advice on project proposals, has consulted with faculty development liaisons on professional development-related issues, and has reported school/division and college accomplishments at faculty meetings. We believe such efforts by the dean have not required a lot of time and effort, and have underscored the importance of the faculty development effort, the liaisons' work, and the work of the school/division faculty development committees.

\section{Meeting the Challenge}

The decentralized model at our college was piloted for one year in the School of Business Careers. Lang and Conner (1988) describe how the various low-budget strategies implemented successfully in this pilot program have remained popular and useful through five years of evolution. Since the pilot year, however, funds for new initiatives and events that bring in external speakers have further enriched the programs.

An important feature of these programs has been the involvement of the faculty development liaisons and school committees in every phase of budgetary planning. They are responsible for determining how the division allocations will be spent to meet the needs expressed by their colleagues. The liaison and advisory group may thus restructure the 
programs to accommodate the changing needs of the school faculty. If they wish, they may pool funds for cross-divisional faculty development events. When financial restraint becomes necessary across all college programs, the dean asks the liaisons, as a team, to determine how their allocations will be affected. The Office of Faculty Development serves as a coordinating and support unit for faculty development liaisons, school committees, and faculty as the program is planned and executed. While each division maintains autonomy in programming and budget planning, OFD provides the college-wide framework for the program and facilitates cross-divisional communication. In this sense, it is the heart of the system and its value is recognized by administrators, faculty development liaisons, and the faculty in general.

When costs and faculty participation factors are both considered, the grassroots model appears to us to be much more efficient. The transition from a centralized department to a school-based grassroots model resulted in reduced costs, in part because two of the four full-time positions in the former "centralized" program were phased out when the part-time faculty development liaison roles were created. Some funds from OFD were distributed to each division on a per capita basis, and additional funds were set aside to support the liaisons by providing released time. With its reduced staff, OFD was able to continue its in-service and chairperson training responsibilities and to provide guidance and coordinating support for faculty development efforts in the divisions.

Since then, institution-wide budget constraints have resulted in a 37 percent decrease in the funds available for faculty development. Despite these budget reductions, however, there has been a ten-fold increase in the number of major presentations, workshops and other structured experiences for the faculty. An average of more than 120 workshops and presentations per year has been reported collectively by the six schoolbased faculty development programs over the past few years. Many other informal activities and projects, such as small incentive grants and brown bag lunch discussions, have also resulted in increased participation by the faculty.

An evaluation form is used with each activity to see if the faculty are satisfied with its content as well as to seek ideas for follow-up. Each of the six divisions also conducts an end-of-year evaluation of the entire program and presents a comprehensive report to the dean. This report includes recommendations from the faculty on issues to be addressed and direc- 
tions to be taken during the next year to enable the concept of a facultygoverned program to continue to evolve.

The number of faculty members participating in the planning, implementation, and evaluation of the program continues to be high. The advisory committees involve six part-time faculty development liaisons and more than 30 department representatives; this means that, at any particular time, about 15 percent of the faculty are actively involved with the issues. In addition, these positions and responsibilities change periodically, and thus provide for an even wider range of faculty to remain cognizant of the goals and value of the program. The advisory groups have included faculty from all ranks, tenured and untenured; we note that many of the "neediest" faculty have been attracted to this opportunity for institutional service.

While such data may generally satisfy our faculty and administrators, we are not without "growing pains," however. We face the typical concerns so frequently reported in the faculty development literature. These include the issues of meeting the wide diversity of faculty needs, particularly on a divisional level; dealing with questions about the value of expending time and energy on such efforts when some wonder whether, for promotion and tenure purposes, energy might be better spent on publishing or presenting externally; involving the senior professoriate both in identifying and addressing their own needs, and in serving as models for less-experienced colleagues; and duly recognizing those who participate in the program. Another issue we will continue to address over the next few years is that of the administrator as colleague. For example, we must confront such questions as: (a) When is a chairperson or assistant dean also a faculty member, and how does this distinction cloud the issue of governance? (b) How can administrators participate in scholarly issues without being intrusive? and (c) To what extent do administrators feel that the faculty development program also meets their professional and personal development needs? These are important concerns that will influence the continued vitality of the program.

\section{Conclusions}

Assuring that faculty members have the authority and responsibility for planning their own development and implementing their own program guarantees faculty governance of the program. This approach has resulted in a healthy and constructive collegial dialogue among faculty, chairpeople, and upper level administrators at our institution. Administrators share a natural tendency to want to assert themselves in processes and 
take control; the dean can speak from personal experience about his own tendencies in this regard. Resisting this disposition and facing it openly when it emerges, as it surely will, is necessary if faculty members are to retain real ownership of their faculty development program. When faculty governance of a faculty development program is introduced, these inherent conflicts must be anticipated and confronted, and solutions must be negotiated among all those involved (Turner and Boice, 1986). Key to success in a faculty development program is open and continued dialogue among faculty members, and between faculty and administrators. We have been attempting to promote this exchange. The most important part of this exchange, however, is the discussion of how well the faculty development program facilitates teaching and learning - the fundamental goals of the academic enterprise.

\section{References}

Eble, K. E., \& McKeachie, W. J. (1985). Improving undergraduate education through faculty development. San Francisco: Jossey-Bass.

Lang, H. G., \& Conner, K. (1988). Some low-budget tips for faculty development programming. In E. C. Wadsworth (Ed.), Professional and organizational development in higher education: A handbook for new practitioners (pp. 139-143). Professional and Organizational Development Network in Higher Education.

Turner, J. L., \& Boice, R. (1986). Coping with resistance to faculty development. In M. Svinicki, J. Kurfiss, \& J. Stone (Eds.), To improve the academy, 5, 26-36. 


\section{Appendix}

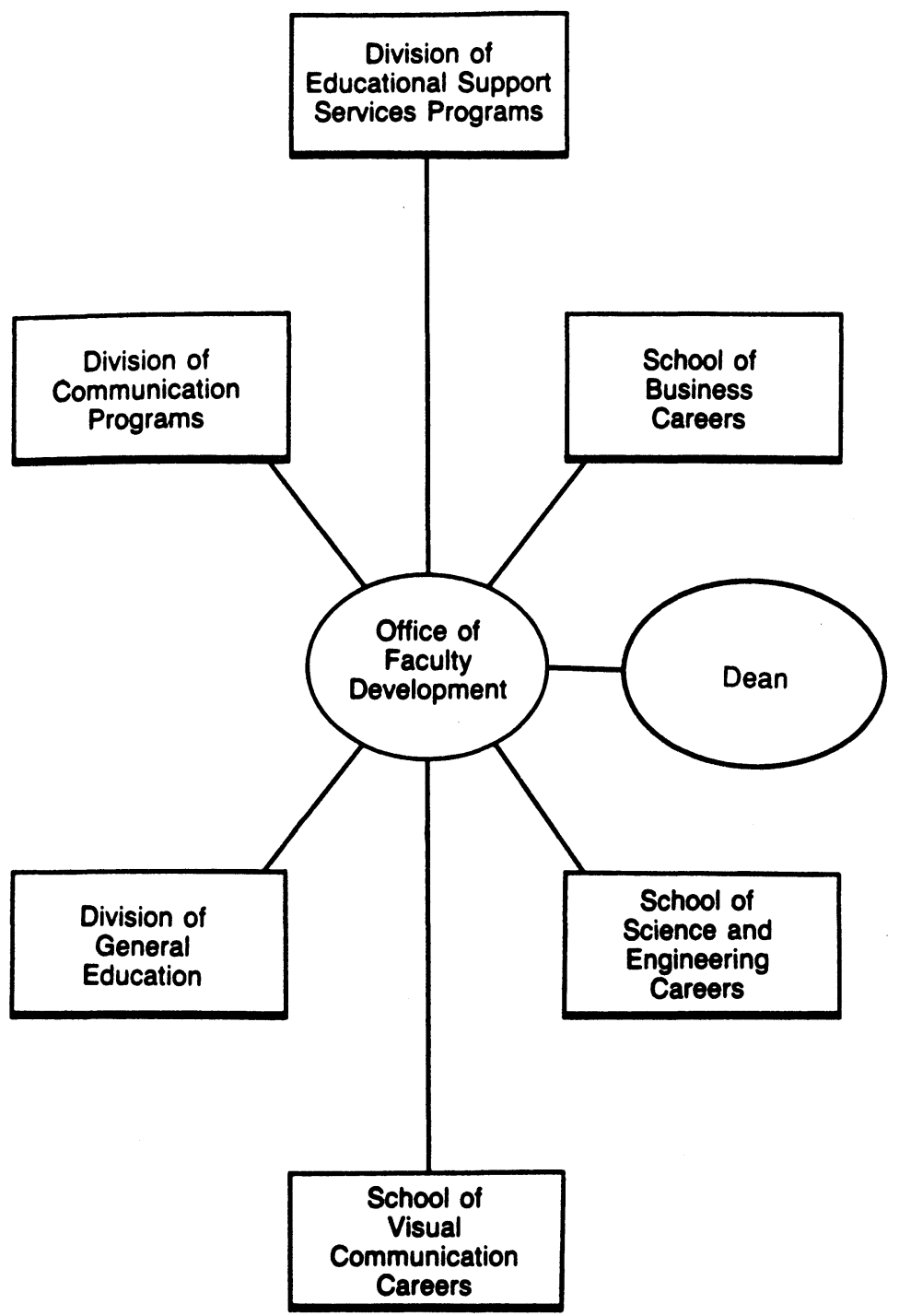

